\title{
Chromosomal Biomarkers in the Clonal Evolution of Head and Neck Squamous Neoplasia
}

\author{
Thomas E. Carey, $\mathbf{P h D}^{1}$, Maria J. Worsham, $\mathbf{M S}^{2}$, and Daniel L. Van Dyke, $\mathbf{P h D}^{2}$ \\ 1 Laboratory of Cancer Biology, Department of Otolaryngology/Head and Neck Surgery, \\ University of Michigan Cancer Center, Ann Arbor,MI 48109-0506 \\ 2 Laboratory of Cytogenetics, Henry Ford Hospital, Detroit, MI 48202
}

\begin{abstract}
The biological behavior of any tumor is the result of changes in gene expression caused by mutations accumulated in the carcinogenic process. In squamous carcinoma of the head and neck (SCCHN) there are numerous complex chromosome abnormalities. To make sense of this complexity it is necessary to identify the consistent chromosome changes in a large panel of tumors, to determine if these changes are true representations of the in vivo situation, and to construct a map of gene loci likely to be involved in the development and progression of cancer. Our findings indicate that cultured tumor cells are cytogenetically stable when compared to cells evolving in vivo. We also found that clues to the sequence of events in clonal evolution of individual tumors can be deduced by studying primary and metastatic tumors from the same patient, by examining separate clones within the same tumor, and by analyzing ploidy changes. Furthermore, comparison of the in vitro karyotypes to in situ analysis of the tumor tissue indicates that in vitro cultures are good representations of the in vivo tumor. We conclude that identification of consistent chromosome changes in cultured cells can lead to the loci of genes important in the clinical behavior of individual tumors. The most frequent chromosome abnormalities in SCCHN, found in 40-60\% of tumors, are deletions affecting $3 p, 5 q, 8 p$, $9 p$, and 18q. Less common consistent changes found in $30-40 \%$ of tumors are gains affecting $3 q, 5 p$, $7 p, 8 q$, and 11q. Preliminary evidence suggests that loss of $18 q$ may be prognostically important and may involve disruption of genes encoding cell adhesion molecules. (C) 1993 Wiley-Liss, Inc.
\end{abstract}

Key words: squamous cell carcinoma, human chromosome deletions, breakpoints and gains, cultured tumor cells, predictive markers

We began our analysis of chromosome abnormalities in squamous cell carcinoma (SCC) to identify the loci of genes likely to be involved in the development and progression of this tumor type. Our hypothesis was based on the same

Abbreviations: der $=$ derived; inv = inversion; $\mathbf{r}=$ ring; $\mathbf{t}=$ translocation; $\mathbf{i}=$ isochromosome, also iso; dup $=$ duplication; add $=$ addition of unknown material; del $=$ deletion.

Address correspondence to Dr. Thomas E. Carey, Laboratory of Head and Neck Cancer Biology, 6020 KHRI, The University of Michigan, 1301 East Ann Street, Ann Arbor, MI 48109-0506.

(C) 1993 Wiley-Liss, Inc. premise as the early studies in leukemias and lymphomas, which postulated that consistent chromosome changes would lead to identification of genes important in the development and evolution of human cancers [1]. For example, the Philadelphia chromosome in chronic myelogenous leukemia was shown to be a $t(9 ; 22)$ translocation, and led to the identification of the $b c r / a b l$ fusion product that activates the $c-a b l$ protein kinase $[2-4]$. Similarly the $t(8 ; 14)$ translocation in Burkitt's lymphoma [5] led to the understanding that a chromosome rearrangement could cause inappropriate expression of a regulatory gene and uncontrolled cell growth by bringing the promoter and enhancer 
elements of an active gene (such as the immunoglobulin genes in the B-cell lineage) into close proximity with c-myc [6]. Similarly, many other consistent rearrangements have provided biomarkers useful in classification and prognosis of individual tumors. Among these is one that is quite relevant to the question of chemoprevention. The $t(15,17)$ rearrangement characteristic of promyelocytic leukemia involves the first intron of the retinoic acid receptor, RAR $\alpha$ [7]. This is intriguing since this form of leukemia has been responsive to treatment with retinoids [8]. As these examples show, knowledge of consistent chromosome changes in tumors can lead to a better understanding of the mechanisms of cancer development and may provide the basis for novel therapies.

\section{IDENTIFYING CONSISTENT CHROMOSOME CHANGES IN HEAD AND NECK CANCER}

Before we began our studies it was clear that the task of defining consistent chromosome abnormalities in SCC would be more difficult than in leukemia because the chromosome abnormalities were more complex and numerous, and there was the added difficulty of obtaining metaphase spreads from solid tumors. In our favor was our experience in culturing squamous cancers, the large panel of squamous cancer lines we had already developed from patients treated in our clinics, and our experience in clinical cytogenetics. The cultured cells made it possible to obtain multiple metaphase spreads and long prometaphase chromosomes so that the banding patterns in enough copies of each rearrangement could be fully analyzed. In this way we could identify nearly all chromosome rearrangements in each tumor for which cell culture was successful.

Analysis of established cell lines clearly showed ways in which squamous cancers differ from leukemias and lymphomas. SCCs have few balanced chromosome translocations and few consistent translocations. Instead, there are frequent, complex translocations, many involving multiple chromosomes. These complex rearrangements often result in chromosome segment losses, which are the most common changes in squamous cancers [9]. The segmental losses are consistent among cell lines and tumors from different individuals, indicating that common genes are lost in the process of cancer progression. There are also a few consistent regions of segmental gains, as well as numerous breakpoints, many of which define the regions of losses and gains [9-11].

Chromosome analysis of cell lines has been subject to criticism. Many observers feel that cell lines do not represent the in vivo situation; that tumor cell lines are unstable in vitro and are under strong selective pressure to overcome the rigors of growth in an unnatural environment by constantly evolving. Although based more on belief than on data, these are valid concerns that require analysis before drawing conclusions about the significance of consistent chromosome changes present in cultured cell lines. Therefore three testable questions were addressed. First, are squamous carcinoma cells karyotypically stable in vitro? Second, are the changes identified in culture also present in vivo, or do these represent adaptations to selective pressures in vitro? Third, do the cells that grow in vitro represent the tumor stem line that persists in vivo? Answering these questions using cytogenetic analysis would provide us with new biomarkers for predicting outcome as well as a much-needed map to genes that determine the biological behavior of individual human cancers.

\section{KARYOTYPIC STABILITY OF SQUAMOUS CARCINOMA CELLS IN VITRO}

Several approaches were employed to address the question of in vitro karyotype stability: analyzing the same cell lines over numerous in vitro passages to identify the frequency of karyotypic changes with time; analyzing mitotic cells in fresh tumor tissue by the use of direct preparations without intervening culture; and examining fresh tumor cultures by in situ analysis on coverslips to compare the first in vitro mitoses to those found in direct preparations versus those found after days, weeks, and months of in vitro cultivation.

The UM-SCC-17A, UM-SCC-17A subline, and UM-SCC-17B cell lines were established from a patient who presented with early stage SCC of the laryn $x$ which was treated initially by radiation. Her tumor progressed during radiation and we received two specimens at the time of laryngectomy. The 17A cell line contained two 
stable and closely related clones that grew from the primary tumor specimen; the $17 \mathrm{~B}$ cell line was from tumor tissue that had spread outside the larynx into the soft tissue of the neck. These cell lines were each karyotyped in multiple passages ranging from 8 to 96 [12]. The consensus karyotype of each cell line was defined as the most consistent chromosome presentation in multiple cells, discounting random losses or gains of individual chromosomes. The consensus karyotype of each of the three sublines was found to be same in all passages analyzed with the exception of passage 56 of UMSCC-17B, where 5 cells were found with a dicentric (dic)(7)(q11.2) replacing a normal 7. In passage 96 of this line, all cells examined had the dic(7). This represents a single in vitro change in three sublines carried over an aggre- gate of 270 passages spanning a period of more than one year and $>1350$ population doublings. These findings indicated that SCC cell lines are generally stable in vitro, but left open the possibility that we had examined the cells after the most rigorous in vitro selection had taken place during the earliest culture history. It was therefore important to examine tumors at the earliest possible stage in vitro and at intervals thereafter if we were to gain a sense of the effects of early evolutionary pressures in vitro.

\section{In Vitro Cultures Represent the In Vivo Tumor}

Among the 29 head and neck squamous carcinomas we have fully analyzed, $1 / 3$ were studied as established cell lines, $1 / 3$ were studied as

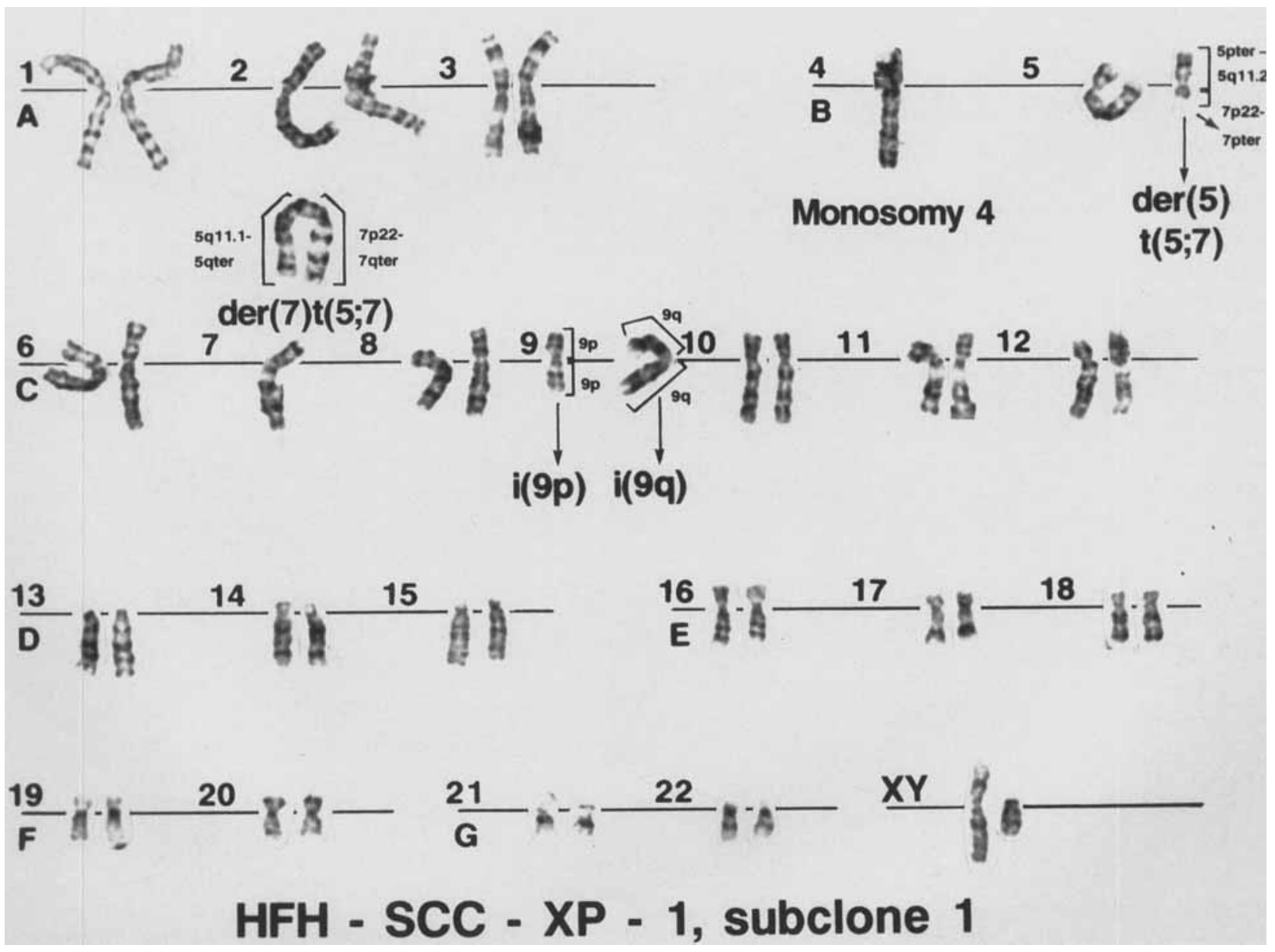

Fig. 1. Karyotype of UM-SCC-XP-1, subclone 1. 45,XY, $-4, t(5 ; 7)(q 11.2 ; p 22), i(9 p)$, $i(9 q)$. This cell is from a primary harvest (passage 0 ) of the fragment 1 culture. Reproduced from Worsham et al. [15] with permission of the publisher. 
direct preparations or early harvests, and $1 / 3$ were analyzed both in direct/early harvests and as established cell lines [Van Dyke, submitted]. These analyses indicate that the same cells that survive in long term culture are representative of dividing cells found in the tumors when they are removed from the patients. We previously reported similar observations for SCC of the vulva $[10,11]$, and endometrial carcinomas $[13$, 14].

One particularly instructive head and neck cancer case we recently analyzed is the HFHSCC-XP-1 tumor [15]. This squamous carcinoma was analyzed in direct preparations, in situ preparations, early harvests, and multiple in vitro passages from separate fragments of tu- mor that were cultured and maintained as though they were from different tumors. Three closely related tumor clones were found. The HFH-SCC-XP-1 cell lines were characterized by monosomy 4, and iso(9p), iso(9q) as early changes shared by all three subclones. Other changes were superimposed on this background, giving rise to three closely related subclones. Subclone 1 was characterized by a $t(5 ; 7)$ balanced translocation (Fig. 1); subclones 2 and 3 both contained monosomy 21 and were distinguished from each other by a der $(11) t(10 ; 11)$ (Fig. 2) in subclone 2 and a der(14)t(13;14) in subclone 3 (Fig. 3). This tumor existed in both diploid and tetraploid versions in vitro. To evaluate the clonal evolution of this tumor, we used

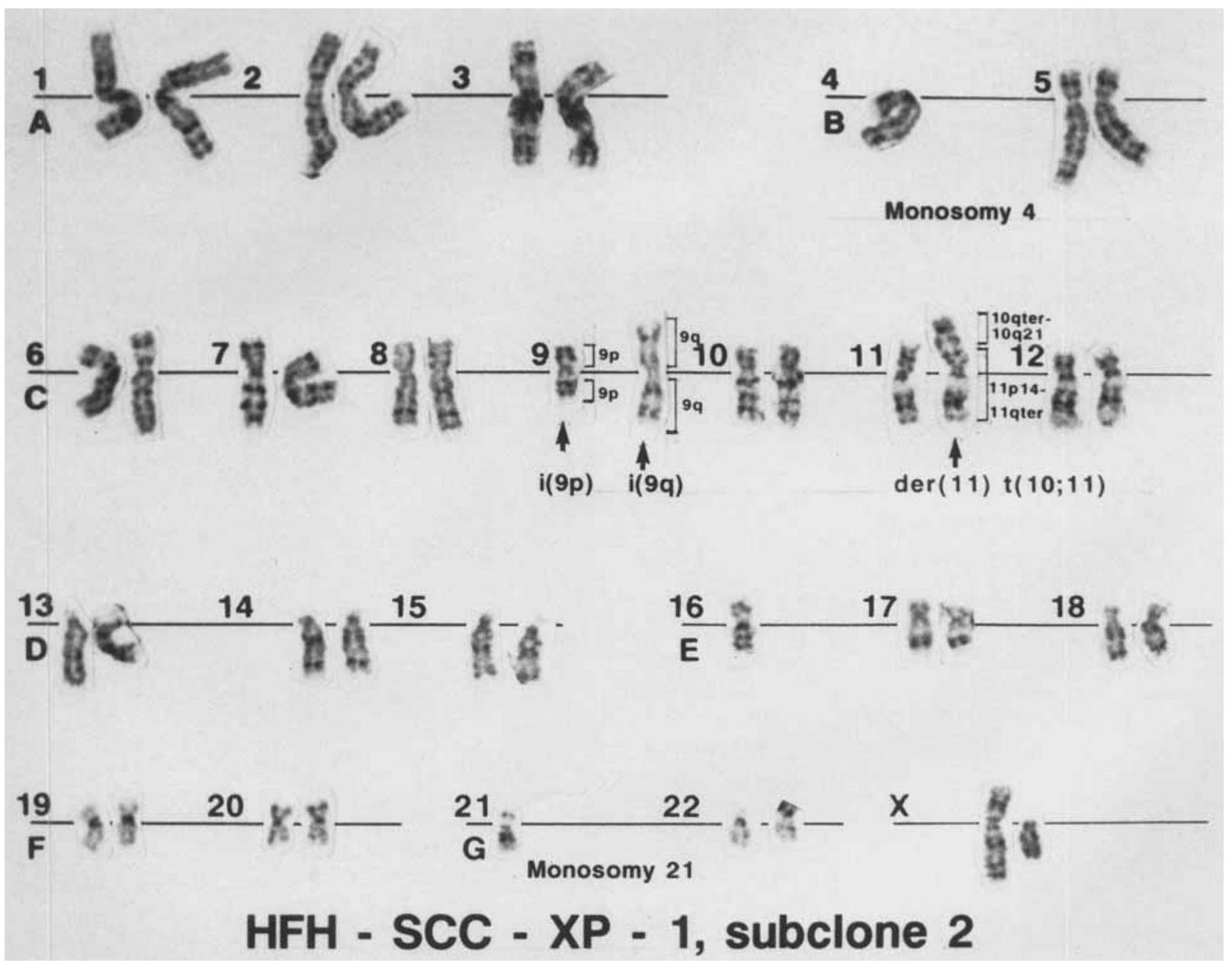

Fig. 2. Karyotype of UM-SCC-XP-1, subclone 2. 44,XY, $-4, i(9 p), i(9 q)$, $\operatorname{der}(11) t(10 ; 11)(q 21 ; p 14),-21$. This metaphase cell was from fragment 1 , passage 0 . Monosomy 16 was present as a random loss in this cell only. Reproduced from Worsham et al. [15] with permission of the publisher. 
these clonal rearrangements and ploidy changes together with the information we obtained by cultivating several tumor fragments as though they were separate tumors.

A flow chart showing all of the karyotyped cells and their relationship to the karyotypic evolution of the primary tumor is shown in Figure 4. The number of cells we karyotyped from each of four tumor fragments is indicated in the small squares in the bottom half of the figure. Fragments 1, 2 and 3 were each studied in several culture passages, as indicated on the left side of the figure. Fragment 4 was analyzed by direct preparation only; two intact mitotic cells were recovered from this procedure. Results from each fragment are separated by dashed horizontal lines. The vertical lines join cells with the same chromosome composition to a circle at the top of the figure where the chromosome makeup of each cell, and its position in the proposed clonal evolution is indicated. Cells which are postulated to exist as intermediates in the clonal evolution, but for which we did not recover an example, are indicated by a broken circle, and cells for which karyotypes have been examined are shown as solid circles. We postulate that the original event began in a normal cell with a 46,XY karyotype. The earliest karyotypic events we could document were loss of 4 and formation of the iso $(9 p)$, iso $(9 q)$ chromosome markers, on which were superimposed either the $t(5 ; 7)$ or loss of 21 plus either the $\operatorname{der}(14)$ or the der(11). Starting from the top left of the figure we can trace the evolution of sub-

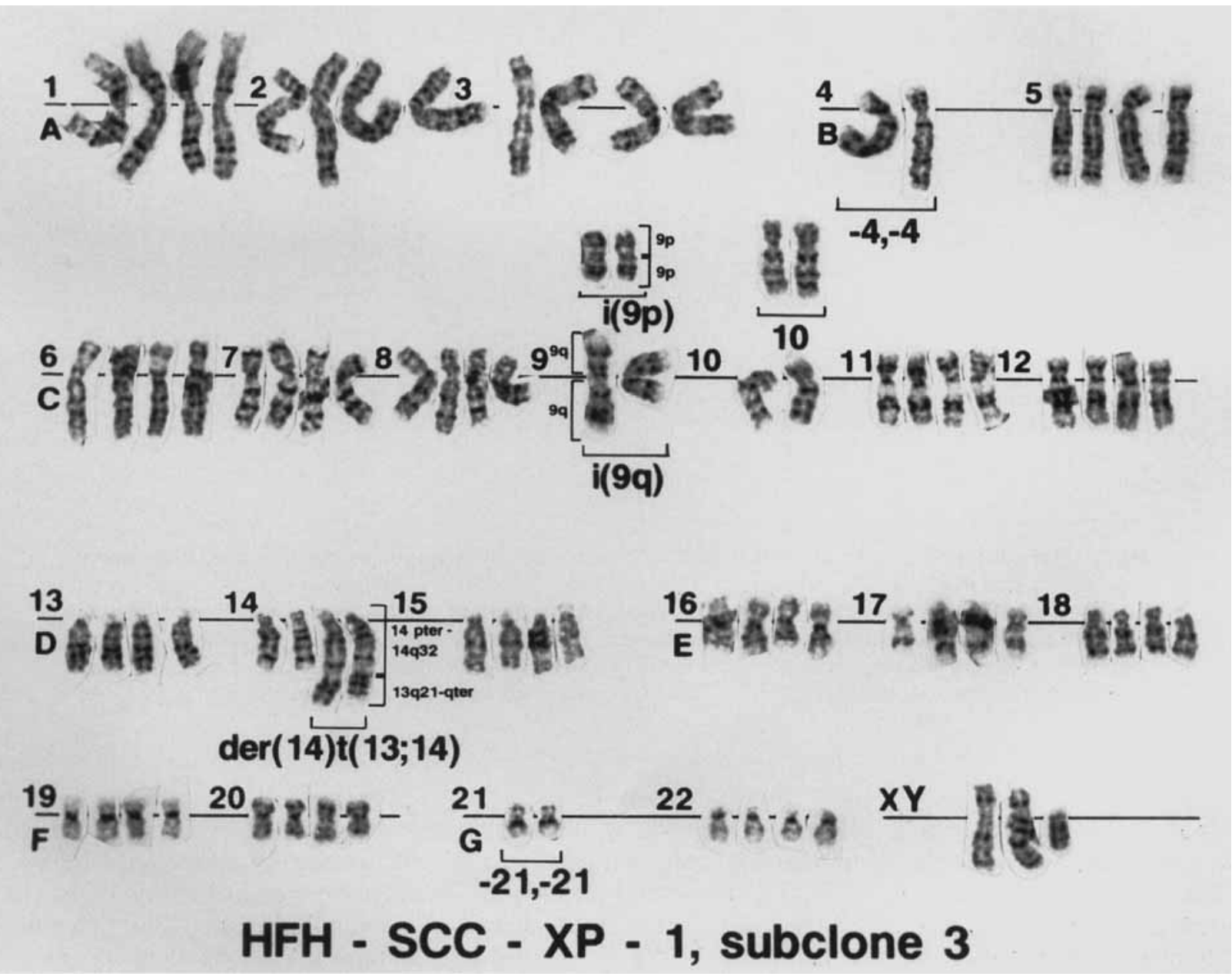

Fig. 3. Karyotype of UM-SCC-XP-1, subclone 3. $87, X X Y,-4,-4$, i(9p), i(9p), i(9q), i(9q), der(14)t(13;14)(q21;p32) $\times 2,-21,-21$. This metaphase cell was from fragment 1 , passage 0 . Reproduced from Worsham et al. [15] with permission of the publisher. 


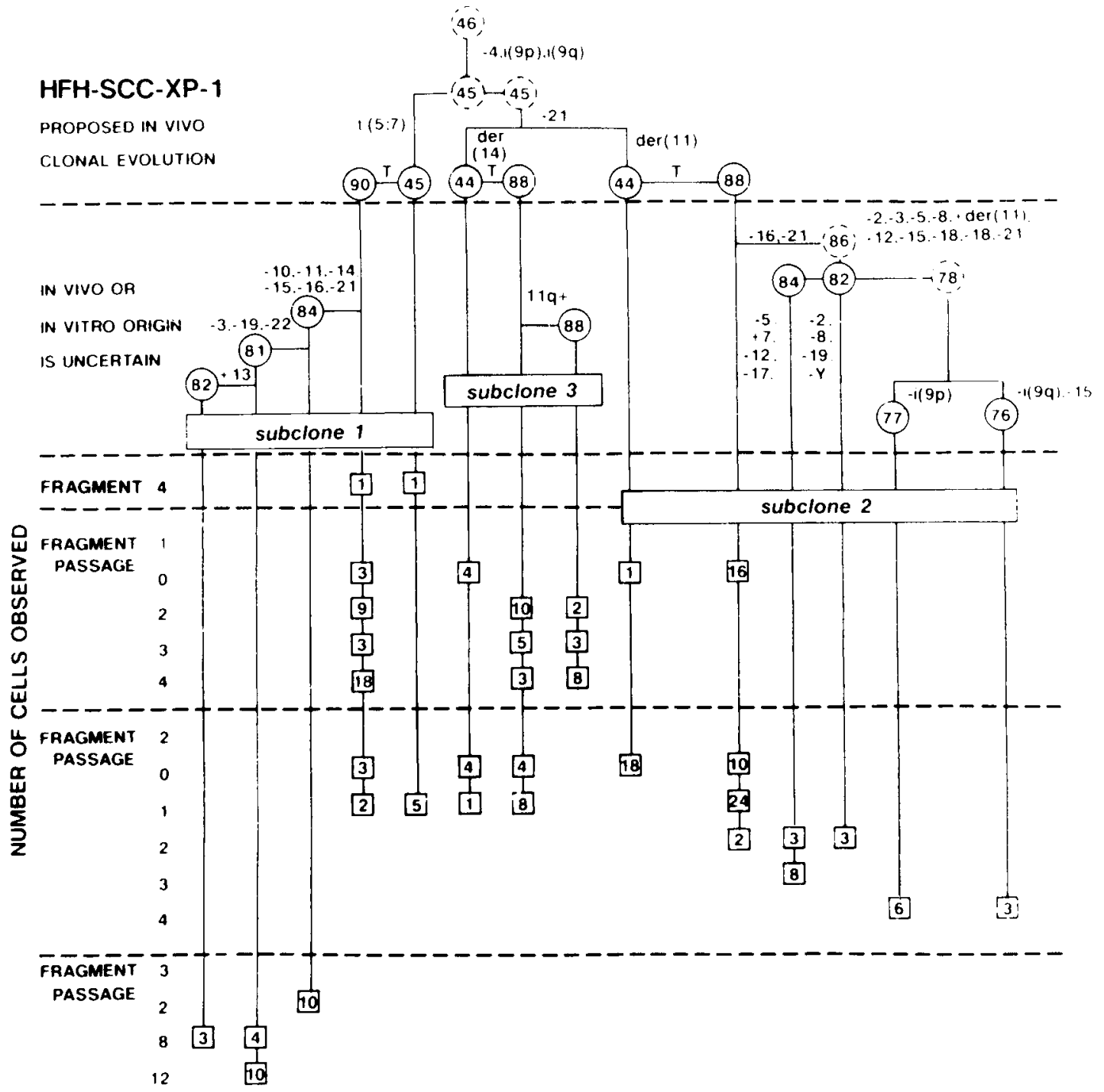

Fig. 4. Proposed clonal evolution of HFH-SCC-XP-1 from a common progenitor cell. The most likely clonal evolution is shown above the solid line. "T" refers to a tetraploidization, endoreduplication, or cell fusion event. Numbers within circles represent the chromosome number. Dotted circles represent probable karyotypic intermediates that were not actually seen. Solid circles represent cells or clones that were identified in culture. Vertical lines connect circles to squares that contain the number of cells analyzed from each passage with the karyotype indicated by the circle. Reproduced from Worsham et al. [15] with permission of the publisher.

clone 1 . We found 6 cells that had only -4 , iso(9p), iso(9q), plus $t(5 ; 7)$ in the karyotype. This karyotype, $45, \mathrm{XY},-4, \mathrm{t}(5 ; 7)(\mathrm{q} 11.2 ; \mathrm{p} 22)$, iso $(9 p)$, iso $(9 q)$, is the primary karyotype of subclone 1 . One cell from tumor fragment 4 was analyzed as a direct preparation. Since it was undergoing mitosis in the tumor, it cannot represent an artifact of culture. Five other cells with the same karyotype were observed in the fragment 2 culture during a passage 1 harvest. Subclone 1 underwent additional changes that began with tetraploidization. The tetraploid version of subclone 1 was observed in one cell from the direct preparation of fragment 4 , indicating that tetraploidy was also an in vivo occurrence. Multiple tetraploid cells of this lineage 
were also present in cultures from fragments 1 and 2 , including 18 cells characterized at passage 4 in the fragment 1 culture. The tetraploid cells continued to evolve further by loss of extra copies of uninvolved chromosomes. Cells with 84,81 and 82 chromosomes were recovered from fragment 3 cultures. It is not possible to determine if these losses were present in vivo or if these occurred in vitro.

Subclones 2 and 3 were detected in the cultures from fragments 1 and 2 . These subclones also existed as both diploid and tetraploid versions. The diploid versions of subclones 2 and 3 were more prominent in early culture, i.e., passage 0 and 1 , whereas the tetraploid versions were more prevalent in passage 2 and higher. Subclone 2 behaved like subclone 1 after tetraploidization and lost chromosomes; cells with $88,84,82,77$ and 76 chromosomes were all recovered in various harvests from fragment 1 and 2 cultures. In contrast, subclone 3 was relatively stable as a tetraploid population; numerous cells with 88 chromosomes were found in several passages. Subclone 3 also gave rise to one additional subclone that was characterized by an $11 q+$.

These observations support the concept that the cells we study as in vitro cell lines are representative of the in vivo tumors. The clones we detected in the earliest in vitro harvests were also represented after days and weeks in culture. Such analysis also helps us to order the events that occur in tumor evolution. For example, specific chromosome losses $(-4,-9,-21)$ and rearrangements were early events, whereas tetraploidization came later. Figure 3 shows a cell with the tetraploid version of subclone 3 . Note that chromosome 4 , the isochromosome $9 \mathrm{~s}$, the der(14), and chromosome 21 are all present as 2 copies; thus each chromosome was present as a single copy before the cell doubled its complement.

We can be reasonably sure that both initial chromosome losses and rearrangements and tetraploidy were in vivo events because we found dividing cells with these changes in the direct preparation and in primary culture. Nevertheless, it is important to confirm by other approaches that the chromosome changes were present in vivo. We applied fluorescence in situ hybridization, a powerful new technique in this case. By using specific probes for chromosomes
4, 17 and the $X$ chromosome, we were able to show that the tumor tissue contained cells with a single signal for chromosome 4 , two for 17 , and 1 for $X$ as expected in the diploid version of this tumor. We also found tumor populations with 2 signals for 4 and $\mathrm{X}$ and 4 signals for 17 , indicating that the tumor had become tetraploid in vivo and not in vitro. We conclude that what we see in in vitro culture is a good representation of what has occurred in vivo. The loss of extra copies of uninvolved chromosomes that occurs after tetraploidy is also a common event; many squamous carcinomas have chromosome counts or DNA content that fall in the hypotetraploid to triploid range [9-11]. This apparently random loss of supernumerary chromosomes makes sense; chromosomes not involved in cancer development most likely do not confer a selective advantage to the cell and may even hinder cell growth by increasing the requirement for additional DNA synthesis.

\section{IN VITRO CULTURES AND THE IN VIVO TUMOR STEM LINE}

We also asked whether cells that grow out in vitro are representative of cells that proliferate as the tumor stem line in vivo. This question can be addressed in part by analysis of cell lines established from both primary and recurrent or metastatic tumors from the same patient. We already described the UM-SCC-17A and 17B cell lines, separately derived from the primary site and from a metastatic tumor in the same patient at the time of laryngectomy. Although these cells were very stable in vitro, there were numerous differences that distinguished the two cell lines, indicating that substantial in vivo evolution had occurred independently in each clone. Nevertheless, each line contained 5 identical changes that we consider to be relatively early events in this tumor. This is shown schematically in Figure 5, where all changes in UMSCC-17A are shown on the left and all changes in UM-SCC-17B are shown on the right. Clearly the two stemlines diverged substantially from one another in vivo, but when placed in culture, each was like a snapshot of the tumor at the time of surgery. Comparing the changes common to both lines makes it possible to see which events had occurred by the time the lines became separate clones. 


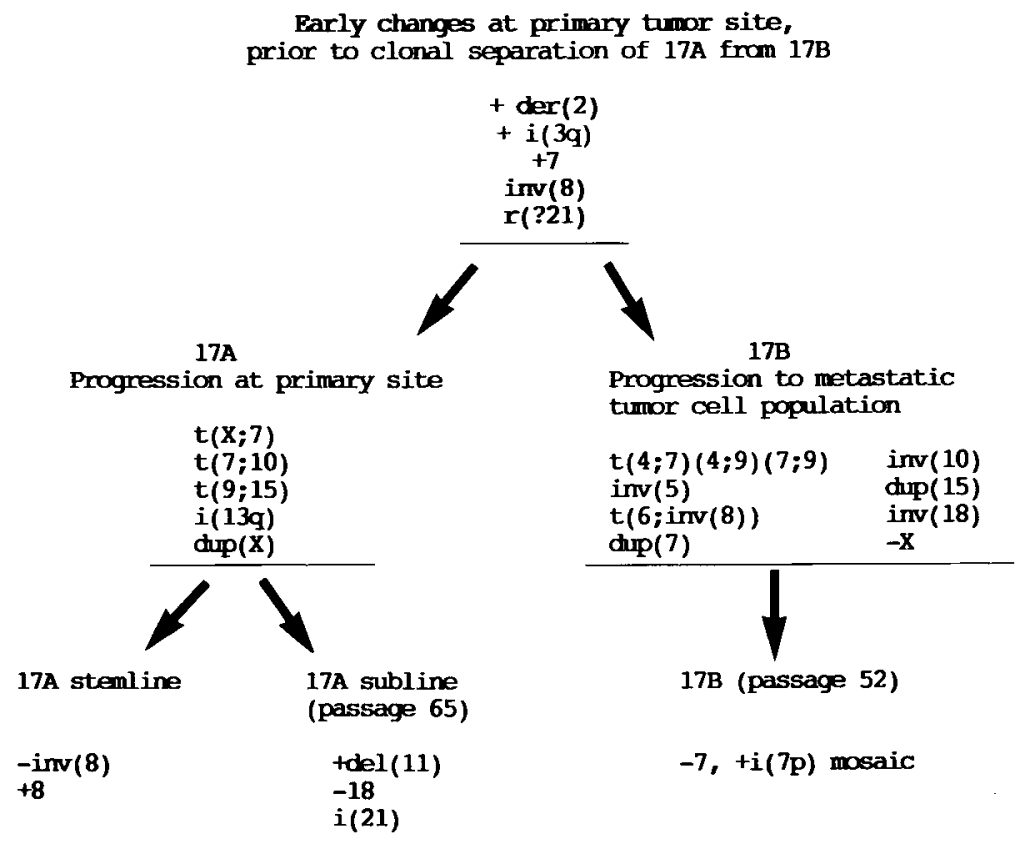

Fig. 5. Postulated sequence of chromosome changes that occurred during the development and progression of the UM-SCC-17 tumor. Reproduced from Carey et al., [12] with permission of the publisher.

This same type of comparison can be made with other cell lines from primary and metastatic tumors from the same patient. In the case of the UM-SCC-21A and 21B cell lines, the first specimen came from a tumor which persisted at the primary site after several resections and radiation treatment failures. The second specimen came from a metastatic tumor in the submandibular gland that was removed 14 months later. This case provided us with insight into the degree of change that occurs in the tumor stem line in vivo. Several characteristic and distinctive chromosome changes were common to both the primary and metastatic tumor. These are shown in the first column of Table I. In addition, each cell line contained unique changes (shown in columns 2 and 3 ), indicating that significant changes occurred in both tumors. The two clones must have diverged well before the surgery from which the first specimen was received; the metastatic cells must have already left the primary site while it was still being treated. Nevertheless, the initial changes common to both the primary and metastatic stemlines were recovered in both in vitro cell lines showing that the cultured cells represent cells that persist in vivo.
The analysis of these three tumor systems, UM-SCC-17A and 17B, HFH-SCC-XP1, and UM-SCC-21A and $21 \mathrm{~B}$, as well as others $[9,10]$, illustrate karyotypic evolution with tumor progression. All indicate that evolution in vivo is greater than that which occurs in vitro, and each supports the concept that cells which grow out in culture represent the stage of tumor evolution at the time the specimen is removed.

\section{Consistent Chromosome Changes in Squamous Carcinomas of the Head and Neck}

In leukemias and lymphomas, analysis of both fresh leukemic cells and of leukemic cell lines demonstrates the same consistent chromosomal markers $[2,3,5,7]$. Based on the data briefly reviewed above, we conclude that the chromosome changes we have documented in our compiled series of 29 head and neck tumors are likewise representative of the consistent changes that characterize human head and neck cancers in vivo. Now the question arises: are any of these consistent changes useful as predictive markers? In compiling our data we observed that one change, loss of $18 \mathrm{q}$, is not only a very 
TABLE I. Karyotypic Evolution of UM-SCC-21A and 21B

\begin{tabular}{|c|c|c|}
\hline \multirow[b]{2}{*}{$\begin{array}{l}\text { Chromosome Rearrangements } \\
\text { Common to Both Tumors }\end{array}$} & \multicolumn{2}{|c|}{ Unique Chromosome Rearrangements } \\
\hline & $\begin{array}{c}\text { UM-SCC-21A } \\
\text { (Primary tumor) }\end{array}$ & $\begin{array}{c}\text { UM-SCC-21B } \\
\text { (Metastatic tumor) }\end{array}$ \\
\hline \multirow{4}{*}{$\mathrm{i}(1 \mathrm{q})$} & & $\operatorname{der}(\mathrm{X}) \mathrm{t}(\mathrm{X} ; \mathrm{X})(\mathrm{p} 22.3 ; \mathrm{q} 13),-\mathrm{Y}$ \\
\hline & $\operatorname{der}(2) \mathrm{t}(2 ; 3)(\mathrm{p} 24 ; \mathrm{p} 22)$ & +2 \\
\hline & $\operatorname{der}(3) t(1 ; 3)(\mathrm{p} 31 ; \mathrm{p} 13)$ & $\begin{array}{l}\operatorname{der}(3) \mathrm{i}(3 \mathrm{q}) t(1 ; 3)(1 \mathrm{pter} \rightarrow \\
\text { p13::3q29 } \rightarrow \text { cen } \rightarrow 3 q \text { ter })\end{array}$ \\
\hline & $\operatorname{inv}(4)(\mathrm{p} 14 \mathrm{p} 16)$ & +4 \\
\hline$i(5 p)$ & & $\mathrm{i}(5 \mathrm{q})$ \\
\hline \multicolumn{3}{|l|}{$\operatorname{dic}(5 ; 6)(\mathrm{p} 11 ; \mathrm{q} 11)$} \\
\hline$i(7 p)$ & & $i(7 p) \times 2$ \\
\hline \multirow{8}{*}{$\begin{array}{l}\operatorname{der}(13) i(13 q) \operatorname{del}(13) \\
(13 q \operatorname{ter} \rightarrow 11.2:: \\
13 q 11.2 \rightarrow q 21:: q 14 \rightarrow q \text { ter })\end{array}$} & & $\begin{array}{l}-8, \mathrm{i}(8 \mathrm{p}), \operatorname{der}(8) \mathrm{t}(8 ; 21)(\mathrm{p} 11.1 ; \\
\mathrm{q} 11.1) \times 2\end{array}$ \\
\hline & $(0,10>\mathrm{q}=0, \mathrm{q}=1)$ & $\mathrm{i}(11 \mathrm{q})$ \\
\hline & $\operatorname{der}(12) t(12 ; 14)(q 22 ; q 24)$ & $\operatorname{add}(12)(q 11)$ \\
\hline & $\operatorname{del}(13)(q 22 q 23)$ & \\
\hline & $\operatorname{der}(15) t(9 ; 15)(q 13 ; p 11)$ & $\operatorname{der}(15) t(8 ; 15)(\mathrm{q} 11.2 ; \mathrm{p} 11.2)$ \\
\hline & -18 & \\
\hline & -19 & \\
\hline & $+\operatorname{mar}$ & +20 \\
\hline
\end{tabular}

frequent event [16] but it is also more frequently present in tumors from patients who have died of their disease than it is in those from patients who are alive and well. We first noticed loss of $18 q$ as a possible marker of aggressive squamous cancers in our analysis of vulvar carcinomas $[10,11]$. Of six patients we studied, there were numerous consistent chromosome changes. Among the common abnormalities there were two segmental losses, $10 \mathrm{q} 23-\mathrm{q} 25$ and $18 q 22-q 23$, that occurred in all 4 of the patients who died of their disease but did not occur in two patients who remain alive and well [10]. Although the numbers are very small, this observation alerted us to the possibility that one or both of these chromosome abnormalities might be associated with poor prognosis. In the SCCHN tumors analyzed thus far, loss of 18q22-q23 has been noted in more than half of the cases $(15 / 29)$. Of the patients whose tumors exhibited loss of 18q, more than $90 \%(14 / 15)$ have died. In contrast, of the patients whose tumors did not exhibit loss of $18 \mathrm{q}$, only $28 \%$ $(4 / 14)$ have died. These findings are provocative and suggest that a gene or set of genes that contribute to the malignant behavior of SCC may be located in this region. Clearly, prospective analysis of $18 \mathrm{q}$ loss as a prognostic indicator is necessary, as is further work to identify the important genes in this region. The deleted 
in colon cancer (DCC) gene [17] has been a valuable marker for analyzing loss of $18 \mathrm{q}$ [16], but thus far we have no evidence that this gene is expressed in normal squamous epithelium. In any case, it serves as a probe for examining loss of this region in fresh tumors and may therefore serve as a good biomarker of highly aggressive neoplasms.

Of special interest for tumors of the squamous epithelia are the recent observations that the desmoglein 1 and pemphigus vulgaris genes are both on chromosome 18 [18]. These proteins are components of the desmosomes, special structures that form intracellular connections between squamous epithelial cells. Loss of function of either of these genes in squamous tumors could lead to increased metastatic behavior by reducing cell-to-cell interaction.

In summary, we have shown how early and established cultures can be used to define the recurrent chromosome changes in SCCHN. Changes found in vitro correspond to in vivo changes. Certain of these chromosome abnormalities may serve as biomarkers of aggressive behavior, and may be useful in screening early stage tumors for those at highest risk of relapse and progression.

\section{REFERENCES}

1. Rowley JD: Molecular cytogenetics: Rosetta stone for understanding cancer. Cancer Res 50:3816-3825, 1990.

2. Nowell PC, Hungerford DA: A minute chromosome in human chronic granulocytic leukemia. Science 132:1497, 1960.

3. Rowley JD: A new consistent abnormality in chronic myelogenous leukemia. Nature 243:290-293, 1973.

4. Witte ON: Role of the BCR-ABL oncogene in human leukemia: Fifteenth Richard and Hilda Rosenthal Foundation Lecture. Cancer Res 53:485-489, 1993.

5. Manlov G, Manlova Y: Marker band in one chromosome 14 from Burkitt's lymphoma. Nature 237:3334, 1972.

6. Adams JM, Harris AW, Pinkert CA, Corcoran LM, Alexander WS, Cory S, Palmiter RD, Brinster RL: The c-myc oncogene driven by immunoglobulin enhancers induces lymphoid malignancies in transgenic mice. Nature 318:533-538, 1985.

7. Borrow J, Goddard AD, Sheer D, Solomon E: Molecular analysis of acute promyelocytic leukemia breakpoint cluster region on chromosome 17 . Science 249:1577-1580, 1990.

8. Huang ME, Ye YC, Chen SR, Chai JR, Lu JX, Zhoa
L, Gu LJ, Wang ZY: Use of all-trans-retinoic acid in the treatment of acute promyelocytic leukemia. Blood 72:567-572, 1988.

9. Van Dyke DL, Worsham MJ, Benninger MS, Gasser $\mathrm{K}$, Schwartz DR, Carey TE: The most frequent chromosome changes in 20 squamous cell carcinomas of the head and neck are deletions. Proc Am Assoc Cancer Res 32:29, 1991 (abstract).

10. Worsham MJ, Van Dyke DL, Grenman SE, Grenman R, Hopkins MP, Roberts JA, Gasser K, Schwartz DR, Carey TE: Consistent chromosome abnormalities in squamous cell carcinoma of the vulva. Genes Chrom Cancer 3:420-432, 1991.

11. Grenman SE, Van Dyke DL, Worsham MJ, England B, McClatchey KD, Hopkins MP, Babu VR, Grenman R, Carey TE: Phenotypic characterization, karyotype analysis and in vitro tamoxifen sensitivity of new ER-negative vulvar carcinoma cell lines, UMSCV-1A and UM-SCV-1B. Int J Cancer 45:920-927, 1990 .

12. Carey TE, Van Dyke DL, Worsham MJ, Bradford CR, Babu VR, Schwartz DR, Hsu S, Baker SR: Characterization of human laryngeal primary and metastatic squamous cell carcinoma cell lines UMSCC-17A and UM-SCC-17B. Cancer Res 49:60986107, 1989.

13. Grenman SE, Van Dyke DL, Worsham MJ, del Rosario F, Roberts JA, McClatchey KD, Schwartz DR, Babu VR, Carey TE: UM-EC-1, a new hypodiploid human cancer cell line derived from a poorly differentiated endometrial carcinoma. Cancer Res 48:1864-1873, 1988.

14. Grenman SE, Worsham MJ, Van Dyke DL, England B, McClatchey KD, Babu VR, Roberts JA, Maenpaa $J$, Carey TE: Establishment and characterization of UM-EC-2, a tamoxifen-sensitive, estrogen receptornegative human endometrial cell line. Gynecol Oncol 37:188-199, 1990.

15. Worsham MJ, Carey TE, Benninger MS, Gasser KM, Kelker W, Zarbo RJ, Van Dyke DL: Clonal cytogenetic evolution in a squamous cell carcinoma of the skin from a xeroderma pigmentosum patient, HFH-SCC-XP-1. Genes Chrom Cancer, 1993 (in press).

16. Kelker W, Van Dyke DL, Worsham MJ, Benninger MJ, James CD, Carey TE: Molecular zygosity analysis of the DCC gene at $18 \mathrm{q} 21.3$ confirms high frequency cytogenetic loss in squamous cell carcinoma. Proc Am Assoc Cancer Res 33:264, 1992.

17. Fearon E, Cho KR, Nigro JM, Kern SE, Simons JW, Ruppert JM, Hamilton SR, Preisinger AC, Thomas G, Kinzler KW, Vogelstein B: Identification of a chromosome 18q gene that is altered in colorectal cancers. Science 247:49-56, 1990.

18. Arnemann J, Spurr NK, Buxton RS: The human gene (DSG3) coding for the pemphigus vulgaris antigen is, like the genes coding for the other two known desmogleins, assigned to chromosome 18. Hum Genet 89:347-350, 1992. 